\title{
Reading and Non-word Repetition Skills in Bilingual Developmental Dyslexia: The Case of a Greek - Italian Bilingual Dyslexic Adult
}

\author{
Ioanna Talli ${ }^{1, *} \&$ Polyxeni Emmanouil ${ }^{1}$ \\ ${ }^{1}$ Dept. of Italian Language \& Literature, Aristotle University of Thessaloniki, PO Box 54124, \\ Thessaloniki, Greece \\ *Corresponding author: Dept. of Italian Language \& Literature, Aristotle University of \\ Thessaloniki, PO Box 54124, Thessaloniki, Greece. Tel: 30-697-656-6206. E-mail: \\ tallijoan@yahoo.com
}

Received: February 6, 2020 Accepted: April 10, 2020 Published: May 8, 2020

doi:10.5296/ije.v12i2.17010 URL: https://doi.org/10.5296/ije.v12i2.17010

\begin{abstract}
Studies of bilinguals with developmental dyslexia learning to read in two alphabetic orthographies have shown that they demonstrate similar reading and phonological short-term memory (STM) deficits in both their languages. The present study aimed at exploring whether dyslexia in adults affects similarly decoding skills in two transparent languages, Greek and Italian, whether there are similar deficits in phonological STM and whether the dominance of one of the two languages affects the manifestation of the deficits. We compared the performance of a young Greek-Italian bilingual dyslexic adult (exposed to Italian from birth, L1: Greek) to that of a young monolingual Greek dyslexic adult, a young Greek-Italian typically developing (TD) bilingual adult (exposed to Italian from birth, L1: Greek) and a young Greek monolingual TD adult. We assessed them in word and non-word reading and non-word repetition. Results showed that bilingual dyslexic adult performed significantly poorer than the bilingual TD adult on all tasks in both languages, suggesting that dyslexia affects similarly decoding and phonological STM across languages. On reading, bilingual outperformed monolingual dyslexic, while monolingual outperformed bilingual TD adult. On phonological STM, both bilinguals outperformed monolinguals. A positive effect of bilingualism was found for reading skills only for dyslexics, while it was found for phonological STM for both dyslexic and TD adults. Finally, the dominance of L1 affected bilinguals' performance in reading but not in non-word repetition, where they showed better performance in Italian, perhaps due to the phonotactic complexity of the Greek orthography compared to Italian.
\end{abstract}

Keywords: developmental dyslexia, bilingualism, decoding, phonological short-term memory 


\section{Introduction}

Developmental dyslexia is a disorder characterized by deficits in reading and spelling words and non-words despite normal intelligence, adequate school opportunities and in absence of physical and neurological deficits (Lyon, Shaywitz, \& Shaywitz, 2003). It is the most common learning disorder. Deficits in reading and spelling constitute the most evident symptoms of dyslexia and are more marked in languages with opaque orthographic systems, such as English, compared to languages with transparent orthographic systems, such as Italian or German (Wimmer, 1993). Numerous researchers have proposed that dyslexia stems from a core phonological deficit (Rack, 2017; Ramus \& Szenkovits, 2008; Snowling, 1998; Vellutino, Fletcher, Snowling, \& Scanlon, 2004; Wimmer, Mayringer, \& Landerl, 1998). Phonological deficit hypothesis is the most prominent hypothesis of dyslexia and is in line with deficits in non-word repetition that are present in dyslexic children (Carroll \& Snowling, 2004; Pennington \& Lefly, 2001; Roodenrys \& Stokes, 2001) and adults (Bruck, 1992; Ramus et al., 2003; Snowling, Nation, Moxham, Gallagher, \& Frith, 1997). Thus, non-word repetition deficits are considered as precursors of dyslexia and markers of literacy difficulties.

\subsection{Word and Non-word Reading and Orthographic Transparency}

The dual route model of reading (Coltheart, 1978; Coltheart, Rastle, Perry, Langdon, \& Ziegler, 2001 ) is the most known model of word and non-word reading. It suggests that readers may use one out of two distinct routes when they are reading: a) the lexical or orthographical reading route (used for familiar and high-frequency irregular words that already exist in reader's lexicon) and b) the sublexical or phonological reading route (based on grapheme-phoneme correspondences and used for reading non-words or unfamiliar words).

Since the foundation of reading is the acquisition of grapheme - phoneme correspondences, differences in orthographic transparency differentially affect the nature and degree of reading difficulties (Seymour, Aro, \& Erskine, 2003). A language whose orthography has almost one-to-one correspondence between graphemes and phonemes is called a transparent orthography (e.g. Italian, Spanish or Greek), while an orthography in which there is not such one-to-one correspondence or it is very rare is called an opaque orthography (e.g. English or French). For example, Italian has 25 sounds and only 33 ways to spell them, while English has 40 sounds and approximately 1.120 ways to spell them (Helmuth, 2001). Researchers have suggested that in languages with a transparent orthography, readers rely mostly on the phonological (sublexical) reading route, which relies on the degree of consistency of the writing system in relation to the spoken language. i.e. grapheme-phoneme correspondences. In contrast, in opaque orthographies such as English, beginning readers rely more on their lexical knowledge. In sum, the process used in learning to read is related to both general principles common to all languages, and to specific characteristics of each language.

\subsection{Developmental Dyslexia across Languages: the Case of Italian and Greek}

It is of crucial importance to know whether the manifestation of dyslexia is the same in countries that use languages other than English, since most research is carried out in 
English-speaking populations. There are few studies that have simultaneously studied dyslexia in two different populations and, while neuroimaging studies suggest that its characteristics are universal, there are behavioral studies that suggest that the nature and prevalence of dyslexia might be different due to differences in orthographies (Landerl, Wimmer, \& Frith, 1997; Paulesu et al., 2001; Sprenger-Charolles, Siegel, Jimenez, \& Ziegler, 2011). Other behavioral studies though suggest that despite differences between different orthographies, the similarities of dyslexic readers are bigger than their differences and that problems are similar across even different orthographies (Ziegler \& Goswami, 2005).

As mentioned earlier, in languages with transparent orthographies, such as Italian and Greek, it is especially difficult to detect developmental dyslexia. In such languages, grapheme phoneme (letter - sound) correspondence is more consistent than in languages with opaque orthographies, such as English, where individuals with dyslexia have more difficulties in reading acquisition (Johansson, 2006; Vellutino et al., 2004) and, thus, dyslexia is easier to diagnose. In a study conducted by Paulesu and collaborators (2001), Italian, English and French dyslexics had all low performance on phonological tasks, but Italian dyslexics performed better on reading comprehension compared to English and French, suggesting that dyslexia is more clearly manifested in languages with opaque orthographies. The difference in performance was attributed to the transparency of the Italian orthography. Paulesu et al. (2001) concluded that there is a universal neurobiological basis for dyslexia, and that differences in reading skills among dyslexics speaking different languages are due to different orthographies and cultural variety. Therefore, dyslexia is called a hidden disorder due to the difficulty of its detection in languages with transparent orthographies, in which manifestations of dyslexia are less severe (Brunswick, 2010).

Non-word reading has been repeatedly found to be problematic among dyslexic readers of transparent orthographies and, thus, it is a reliable measure of dyslexia diagnosis (Greek: Porpodas, 1999; German: Ziegler, Perry, Ma-Wyatt, Ladner, \& Schulte-Koerne, 2003; Spanish: Jiménez Gonzalez, \& Hernandez Valle, 2000; Italian: Chilosi et al., 2003; Facoetti et al., 2006; Paulesu et al., 2001; French: Sprenger-Charolles, 2019; Sprenger-Charolles, Colé, Kipffer-Piquard, Pinton, \& Billard, 2009; Sprenger-Charolles, Colé, \& Serniclaes, 2013). Moreover, cross-linguistic studies suggest that dyslexic readers have difficulties in reading non-words in both transparent and opaque orthographies, which means that they have difficulties with the sublexical route (children: Landerl et al., 2013; adults: Paulesu et al., 2001; Martin et al., 2010). Reading fluency is also a reliable measure for detecting dyslexic readers in transparent orthographies, since they read accurately but more slowly than typical readers (Diamanti, Goulandris, Campbell, \& Protopapas, 2018; Gangl et al., 2018; Wimmer, 2006).

Greek children and adolescences with dyslexia demonstrate deficits in word and non-word reading accuracy and speed, phonological awareness, rapid automatized naming, spelling, stress assignment and verbal working memory (Anastasiou \& Protopapas, 2015; Constantinidou \& Evripidou, 2012; Constantinidou \& Stainthorp, 2009; Diamanti et al., 2018; Protopapas \& Skaloumbakas, 2007; for a review see Protopapas, 2017). Reading speed assessment is considered crucial in Greek reading acquisition (Porpodas, 1999) and reading fluency, which combines accuracy and speed and is considered the most reliable measure of 
distinguishing dyslexic among typically developing readers (Protopapas \& Skaloumbakas, 2008). Consequently, accuracy difficulties are not easily detected among impaired Greek readers (Protopapas, 2017), however reading speed remains slow and labored (Nikolopoulos, Goulandris, Hulme \& Snowling, 2006). Non-word repetition skills are also impaired among Greek dyslexic readers (Mengisidou \& Marshall, 2019; Spanoudis, Papadopoulos \& Spyrou, 2019; Talli, Sprenger-Charolles \& Stavrakaki, 2016).

Italian children with dyslexia demonstrate a deficit in word and non-word reading speed (Brizzolara et al., 2006; Chilosi et al., 2003; Tressoldi, Stella, \& Faggella, 2001; Zoccolotti et al., 1999) and they demonstrate word length effect (Spinelli et al., 2005; Zoccolotti et al., 2005), word frequency effect (Barca, Burani, Di Filippo, \& Zoccolotti, 2006; Burani, Marcolini \& Stella, 2002) and lexicality effect (Burani, Arduino, \& Barca, 2007; Pagliuca, Arduino, Barca, \& Burani, 2008). They also make stress regularisation errors (Paizi, Zoccolotti, \& Burani, 2011; Zoccolotti et al., 1999), which are considered to be linked to reading fluency (Orsolini, Fanari, Cerracchio, \& Famigliette, 2009). Slower reading rates and fluency deficits have been also found in studies of vocal reaction times. Spinelli et al. (2005) found that the latency of onset of words' pronunciation was higher and depended on word length among dyslexics compared to TD readers. The same results have been found by other studies as well (De Luca et al., 2008; Martelli et al., 2014; Paizi et al., 2011; Paizi, De Luca, Zoccolotti, \& Burani, 2013; Zoccolotti, De Luca, Judica, \& Burani, 2006; Zoccolotti, De Luca, Judica, \& Spinelli, 2008). A re-analysis of eleven studies confirmed these findings (Zoccolotti, De Luca, \& Spinelli, 2015). Non-word repetition skills are also found to be impaired in Italian children with dyslexia with co-morbid language deficits compared to dyslexics only (Brizzolara et al., 2006; Chilosi et al., 2009). It has been suggested that non-word repetition deficits stem from a working memory deficit (Beneventi, Tønnessen, Ersland, \& Hugdahl, 2010; Vender, Mantione, Savazzi, Delfitto, \& Melloni, 2017). However, there are studies that suggested that rapid naming tasks are more effective than non-word repetition tasks in detecting dyslexia in Italian and, more generally, in transparent orthographies (Brizzolara et al., 2006; Landerl et al., 2013).

\subsection{Effects of Bilingualism and Multilingualism on Reading and Memory}

Positive effects of bilingualism on reading and memory have been found by several studies on these tasks (word reading: Abu-Rabia \& Siegel, 2003; non-word reading and spelling: Abu-Rabia \& Siegel, 2002; Lesaux \& Siegel, 2003; Siegel, 2016; non-word repetition: Tamburelli, Sanoudaki, Jones \& Sowinska, 2015; semantic memory (Kormi-Nouri, Moradi, Moradi, \& Akbari- Zardkhaneh, 2012). Bonifacci, Canducci, Gravagna, \& Palladino (2017) assessed three groups in Italian and English word and non-word reading tasks (among other tasks): TD Italian monolingual children, Italian monolingual children with dyslexia and TD sequential bilingual language-minority children, who had Italian as L2 and English as a foreign language (L3). They found that TD bilinguals were less accurate in reading Italian than TD monolinguals and more accurate than dyslexics, but had the same reading speed as TD monolinguals in Italian and both reading speed and accuracy in English (L3). They suggested that bilingualism is beneficial for L3 learning, even when L3 is a language with an opaque orthography. In a meta-analysis of 47 studies, Melby-Lervåg and Lervåg (2011) examined the 
cross-linguistic transfer of oral language, phonological awareness and decoding from L1 to L2 and found that for phonological awareness and decoding skills there is a transference of skills from L1 to L2. However, there are studies in which bilingualism has no effect on reading skills (e.g. Zhang, Chin, \& Li, 2017). In general, the effect of bilingualism depends on children's level of language proficiency in L1 and L2 and high levels of proficiency in both languages exhibit more clearly positive results (Bialystok, McBride-Chang, \& Luk, 2005). For example, vocabulary size is an indicator of language proficiency and it has been found that the lexicon size of L2 affects reading performance in adult English-Italian bilinguals (Vender, Delfitto, \& Melloni, 2019). Another indicator and predictor for reading accuracy has been found to be non-word repetition in bilingual children (Bellocchi, Tobia, \& Bonifacci, 2017).

\subsection{Bilingualism, Multilingualism and Developmental Dyslexia}

There are many issues surrounding bilingual (and multilingual) dyslexia. First of all, there is the question that if dyslexic children have reading and STM difficulties in one language, is it possible to learn to read in two or three languages? In other words, is dyslexia transferred across languages? Another question would be whether bilingualism (or multilingualism) itself might be at all helpful or burdensome in the manifestation of the deficits in dyslexia, in sense that it is not sure whether bilingual dyslexics perform the same, better or worse than their monolingual dyslexic peers on reading and STM tasks. Inversely, it is not sure whether bilingual dyslexics have worse or comparable performance in reading and STM compared to TD bilinguals. If bilingualism positively affects dyslexic symptoms, they will then have comparable performance with TD bilinguals. If not, bilingual dyslexics will have worse performance, just like monolingual dyslexics have when compared to monolingual TD. A third question would be whether the amount of exposure and the possible dominance of one language might affect the manifestation of the deficits. A fourth and last question would be whether the orthographic transparency of L1 and/or L2 might affect the dyslexic symptoms in each language.

Regarding the first question, it has been shown that individuals with dyslexia are at high risk of developing reading and writing deficits in second language (L2) learning, since their impaired reading and phonological skills in L1 seem to be transferred to L2 (Chung \& Ho, 2010; Da Fontoura \& Siegel, 1995). Moreover, proficiency levels of reading and writing skills and learning speed in L1 predict L2 acquisition skills in these domains (Sparks, Patton, Ganschow, Humbach, \& Javorsky, 2006).

Regarding the second question, one would expect dyslexic monolinguals to outperform dyslexic bilinguals due to the additional language overload, while others would expect bilinguals to perform better due to the beneficial effect of bilingualism. Research has showed that there are contradictory patterns of results. Vender et al. (2016) found similar performance in non-word repetition between 120 preschool bilingual children (having Italian as L2 and Albanian, Arabic or Romanian as L1) and 40 Italian monolingual children, despite exhibiting difficulties in morpho-syntactic tasks (i.e., clitic production). Jalali-Moghadam and Kormi-Nouri (2017) found that Iranian - Swedish bilingual dyslexic children had lower performance than Swedish monolingual dyslexic children on one task of semantic memory 
(category fluency task), but there was no difference between these groups on the other semantic memory task (letter fluency task). Both are lexical retrieval tasks in which bilinguals are generally slower (Sullivan, Poarch, \& Bialystok, 2018) because they have smaller vocabularies (Bialystok \& Luk, 2012; Bialystok, Luk, Peets, \& Yang, 2010). A study in monolingual and bilingual dyslexic children with Italian as L2 showed more severe deficit in word reading than non-word reading for bilingual dyslexics compared to monolingual dyslexics (Zanzurino, Scortichini, Stella, Morlini, \& Scorza, 2012). However, another study showed that Arabic-English dyslexic bilinguals performed better than English monolingual dyslexics in word and non-word reading (Abu-Rabia \& Siegel, 2002). In this case, bilingualism was beneficial and the authors suggested that there was a positive transfer from Arabic regular orthography to the English orthography.

Inversely, the positive effect (or no effect) of bilingualism on dyslexia can be attested when bilingual dyslexics are compared to TD bilinguals. In a study by Oren and Breznitz (2005), who compared Hebrew-English dyslexic to Hebrew-English TD bilinguals, dyslexic bilinguals had lower performance than TD bilinguals in reading speed (not accuracy) in Hebrew and both reading accuracy and speed in English. They also had lower performance in phonological processing and orthographic ability in both languages. Similarly, Swanson, Saez and Gerber (2006) found that bilingual Spanish-English dyslexic children had lower performance on tasks of English and Spanish reading and working memory and Spanish STM compared to Spanish-English TD children. In these two studies, bilingualism had no positive effect on dyslexics' performance on reading and memory tasks. In another study, Hedman (2012) compared the performance of 10 Spanish-Swedish speaking adolescents with dyslexia and 10 Spanish-Swedish speaking TD adolescents on decoding (word and non-word reading) and STM (non-word repetition) on both languages and found no differences between the two groups on these tasks. Nevertheless, based on individual analysis, she suggested a bilingual dyslexic continuum, from high to no indications of dyslexia, in which cases of under-identification of dyslexia appear.

Regarding the third question pointed out, first of all it has been shown that the amount of language use and the dominance of a language (i.e. the language in which the bilingual individual obtains more input on a regular basis) is strongly related to the performance in this language, including reading skills (Bonfieni, Braningan, Pickering, \& Sorace, 2019; Dickinson \& Porsche, 2011; Monaghan, Chang, Welbourne, \& Brysbaert, 2017; Nota, 2018; Papastefanou, Powell, \& Marinis, 2019; Thordardottir, 2011), as well as age of language exposure (Kovelman, Baker, \& Petitto, 2008). With respect to whether the amount of exposure and the possible dominance of one language might affect the manifestation of the deficits in dyslexia, to our knowledge, there is only one relevant study in the literature to have raised that claim (Lallier, Thierry, Barr, Carreiras, \& Tainturier, 2018) and it is based on the Grain Size Accommodation hypothesis (Lallier \& Carreiras, 2018). This hypothesis makes predictions about how bilingualism interacts with reading and reading-related processes in children and adults with (and without) dyslexia. More specifically, it suggests that the impact of bilingualism on reading (and reading-related skills) depends on the size of the orthographic and phonological grains of each of the two languages learned and that it is not similar across 
bilinguals. For example, in cases of bilinguals who learn languages with difference in orthographic transparency (e.g. L1: transparent and L2: opaque), beneficial reading processes are modulated and transferred from L1 to L2. Lallier et al. (2018) assessed two dyslexic groups: one Welsh-English bilingual adults group and one English monolingual adults group on reading and spelling words and non-words in English, as well as on phonological awareness tasks. They found that dyslexic bilinguals had an advantage on non-word reading and on both spelling tasks, while English monolinguals had better performance on word reading. They didn't find any bilingual advantage on phonological awareness tasks. They explained the bilingual advantage on non-word reading (i.e. better sublexical skills of bilinguals as opposed to better lexical skills of monolinguals) by suggesting that learning to read in a transparent orthography (Welsh) moderated the severity of the deficits in an opaque orthography (English).

Finally, as regards the fourth question, it has been showed that bilinguals perform better in reading in transparent compared to opaque orthographies. For example, in the previously mentioned study by Hedman (2012) with Spanish-Swedish dyslexics and TD adolescences, there was a transparency effect, since bilingual children had better reading performance in Spanish, which has a more transparent orthography than Swedish, in line with other studies showing better reading skills in bilinguals in languages with transparent compared to opaque orthographies (Geva \& Siegel, 2000). In sum, the study of bilingual individuals is a strong case not only to assess bilingualism, but also orthographic transparency effects on reading performance (Dulude, 2012; Cline, 2000). Taken together, the existing literature suggests that the language background (e.g. language dominance, amount of input, age of acquisition of L2) and the orthographic transparency must be taken into account when assessing literacy and cognitive skills in bilinguals but also deficits in dyslexic individuals.

The present study aims to elucidate the nature of bilingual dyslexia in two transparent orthographies (Italian and Greek), to consider the extent to which reading difficulties (word and non-word reading) and VSTM (non-word repetition) deficits differ in the two languages and the extent to which the amount of exposure in both languages or the dominance of one of the two languages affect the manifestation of reading and VSTM deficits in L2 and how. In other words, the goal of this study was to explore cross-linguistic differences in reading and STM skills between L1 and L2 and cross-linguistic transfer of these skills from L1 to L2. Moreover, it aimed to examine whether there is a (positive or negative) effect of bilingualism in the manifestation of the deficits in dyslexia. To our knowledge, no case of Greek - Italian bilingual dyslexic adult has been previously compared at the same time to a monolingual dyslexic adult and to monolingual and bilingual typically developing adults. According to the literature, we expect to find similar performance of the bilingual adults in both transparent languages, lower performance of the monolingual dyslexic compared to the bilingual dyslexic on decoding and STM tasks and better performance of the bilingual TD than monolingual TD on these tasks due to the bilingual advantage. 


\section{Methodology}

\subsection{Participants}

In the present study there were four participants, two Greek - Italian bilingual adults (one with developmental dyslexia and one typically developing) and two Greek monolingual adults (one dyslexic and one typically developing). They were all males aged between 22-26 years old.

The bilingual dyslexic adult was 22 years old, bilingual speaker of Greek and Italian from birth. He was born and raised in Corfu, Greece; his father was Greek (L1: Greek, L2: Italian) and his mother is Italian (L1: Italian, L2: Greek). He went to a Greek school and spoke Italian with his mother and Greek with his father at home, while he learned how to read and write in Italian through tutorial sessions. His dominant language (L1) is Greek. He was diagnosed with developmental dyslexia by a multidisciplinary team of a medical-pedagogical center in Greece at the age of 17 .

The bilingual TD adult was 25 years old, also bilingual speaker of Greek and Italian from birth. He was born and raised in Thessaloniki, Greece; his father was Greek (L1: Greek, L2: Italian) and his mother was Italian (L1: Italian, L2: Greek). He went to a Greek school and spoke Italian with his mother and Greek with his father at home, while he learned how to read and write in Italian through tutorial sessions. His dominant language (L1) was Greek. He had no reading or other known literacy difficulties.

The monolingual dyslexic adult was 26 years old, monolingual speaker of Greek from birth. He was diagnosed with developmental dyslexia by a multidisciplinary team of a medical-pedagogical center in Greece when he was 12 years old.

The monolingual TD adult was 25 years old, monolingual speaker of Greek from birth. He was born and raised in Thessaloniki, Greece, by Greek parents. He had no reading problems or other known literacy difficulties.

\subsection{Materials}

Both bilingual participants were tested in both Greek and Italian measures, while the monolinguals were tested only in Greek tests:

\subsubsection{Greek Tests}

Reading Fluency test. We used the Greek reading fluency test 'Giro giro oli' (adaptation of French reading test 'Alouette', Lefavrais, 1967; Talli, 2010). This test is a composite test of reading ability. It involves reading aloud a 271-word text, which includes low-frequency words and misleading contextual information, therefore it assesses word-level reading skills rather than word-in-context reading. Reading scores are computed by adding the total number of non-corrected errors and the total number of non-read words to the total reading time (calculated with a stopwatch in seconds, with a limit of 180 seconds). This test does not exist in Italian, therefore it was administered in Greek language only.

Word and non word reading. From Word and Nonword list Recall, Paraskevaidis, 2010; adapted from Working Memory Test Battery for Children (Pickering \& Gathercole, 2001). The 
list of 630 bi-syllable words and 330 bi-syllable non-words were administrated for word and non-word reading. The total percentage of errors was taken into account for both tasks.

Non-word repetition. From: Nonword list Recall, Paraskevaidis, 2010; adapted from Working Memory Test Battery for Children (Pickering \& Gathercole, 2001). This task comprised of 330 bi-syllable non-words in lists of increased levels of difficulty (increased by one non-word for each level) and each level had 6 lists of non-words. For example, level 1 had 6 lists of one non-word, level 2 had 6 lists of two non-words, etc. The administration would stop after three unsuccessfully recalled lists out of six in each level. The individual's score was equal to the sum of the word lists correctly recalled (one point for each correct list) and his span was the last level in which he had recalled 4 correct lists. The maximum score could be 60 and maximum span could be 10 .

\subsubsection{Italian Tests}

Word and non-word reading. Part 2 of the Batteria per la valutazione della Dislessia e della Disortografia evolutiva-2, DDE-2 (Sartori, Job, \& Tressoldi, 2007) was administered to assess the students' level of word reading. Children were asked to read aloud four lists of bi- and tri-syllable words of 28 words each. Auto-corrections were considered as correct trials. There were 112 words in total and the score was the number of words correctly read. Percentage of accuracy was also taken into account. Non-word reading was assessed using the repetition of non-words task described here below (VAUMeLF, Bertelli, \& Bilancia, 2006). There were 40 non-words in total and the score was the number of non-words correctly read. Percentage of accuracy was also taken into account.

Repetition of non-words. Batterie per la Valutazione dell' Attenzione Uditiva e della Memoria di Lavoro Fonologica nell' Età Evolutiva (VAUMeLF, Bertelli, \& Bilancia, 2006) was administered to assess phonological STM. The test included 40 non-words (two to five syllables in length), which conformed to the phonotactic rules of Italian language. Children would listen first a non-word and then they were asked to repeat it.

\section{Results}

Table 1 reports total errors (and percentages of errors) of the bilinguals and monolingual adults (dyslexics and TD). As it can be seen, the accuracy scores of the monolingual dyslexic adult was the lowest in all tasks, while bilingual dyslexic adult outperformed monolingual dyslexic adult on all tasks. In Greek, monolingual TD adult outperformed bilingual TD adult on all reading tasks: reading fluency (composite score: 130 for mono-TD vs. 133 for bi-TD), word reading $(0,3 \%$ for mono-TD vs. $0,6 \%$ for bi-TD) and non-word reading $(1,2 \%$ for mono-TD vs. $2,1 \%$ for bi-TD), while the reverse was found for non-word repetition ( $58 \%$ for bi-TD vs. $63 \%$ for mono-TD). Figure 1 illustrates clearly the performance of the four participants on the Greek reading tasks. 
Table 1. Total Errors out of Total Items (and Percentages of Errors) of the Participants in Greek and Italian Word and Non-word Reading and Non-word Repetition Task

\begin{tabular}{|c|c|c|c|c|c|c|c|}
\hline & \multirow{2}{*}{$\begin{array}{c}\text { Reading } \\
\text { fluency test } \\
\text { (composite } \\
\text { score) }\end{array}$} & \multicolumn{2}{|c|}{ Word reading } & \multicolumn{2}{|c|}{ Non-word reading } & \multirow{2}{*}{$\begin{array}{c}\begin{array}{c}\text { Non-word } \\
\text { repetition }\end{array} \\
\text { Greek }\end{array}$} & \multirow{2}{*}{$\begin{array}{c}\begin{array}{c}\text { Non-word } \\
\text { repetition }\end{array} \\
\text { Italian }\end{array}$} \\
\hline & & Greek & Italian & Greek & Italian & & \\
\hline Bi-DD adult & 165 & $\begin{array}{l}10 / 630 \\
(1,6 \%)\end{array}$ & $\begin{array}{c}22 / 112 \\
(19,6 \%)\end{array}$ & $\begin{array}{l}24 / 330 \\
(7,3 \%)\end{array}$ & $\begin{array}{c}14 / 88 \\
(15,9 \%)\end{array}$ & $\begin{array}{l}45 / 60 \\
(75 \%)\end{array}$ & $\begin{array}{l}61 / 88 \\
(69 \%)\end{array}$ \\
\hline Bi-TD adult & 133 & $\begin{array}{c}4 / 630 \\
(0,6 \%)\end{array}$ & $\begin{array}{c}4 / 112 \\
(3,6 \%)\end{array}$ & $\begin{array}{c}7 / 330 \\
(2,1 \%)\end{array}$ & $\begin{array}{c}5 / 88 \\
(5,7 \%)\end{array}$ & $\begin{array}{l}35 / 60 \\
(58 \%)\end{array}$ & $\begin{array}{l}13 / 88 \\
(14 \%)\end{array}$ \\
\hline Mono-DD adult & 172 & $\begin{array}{l}13 / 630 \\
(2,1 \%)\end{array}$ & - & $\begin{array}{l}30 / 330 \\
(9,1 \%)\end{array}$ & - & $\begin{array}{l}48 / 60 \\
(80 \%)\end{array}$ & - \\
\hline Mono-TD adult & 130 & $\begin{array}{c}2 / 630 \\
(0,3 \%)\end{array}$ & - & $\begin{array}{c}4 / 330 \\
(1,2 \%)\end{array}$ & - & $\begin{array}{l}38 / 60 \\
(63 \%)\end{array}$ & - \\
\hline
\end{tabular}

Bi-DD: bilingual dyslexic adult, Bi-TD: bilingual typically developing adult, Mono-DD: monolingual dyslexic adult, Mono-TD: monolingual typically developing adult.

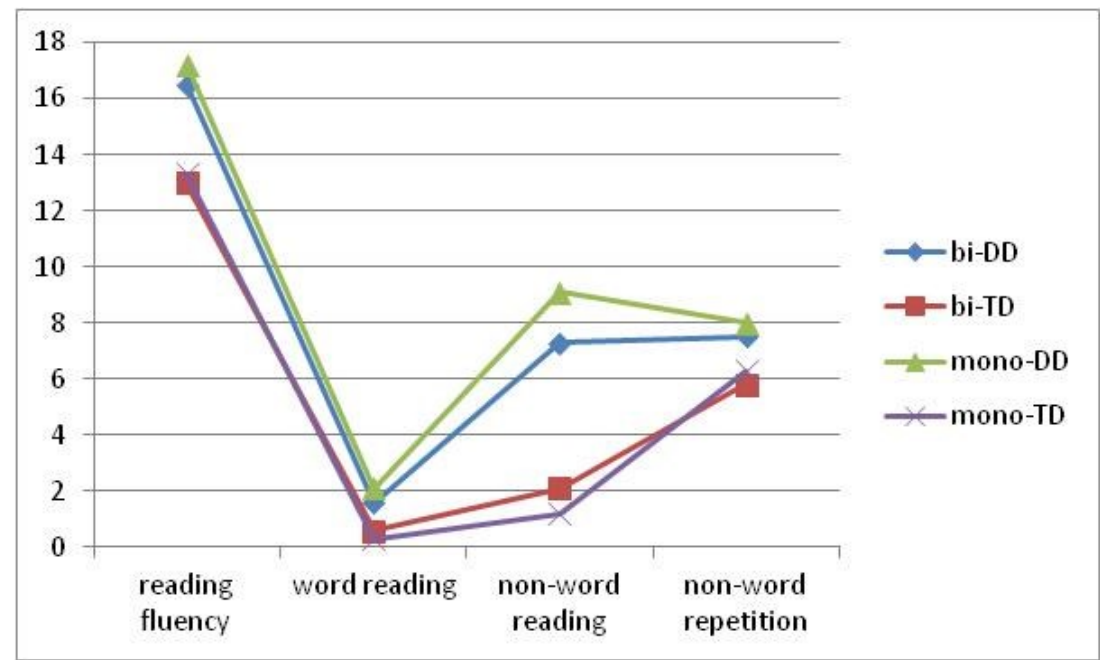

Figure 1. Performance of the Participants on the Three Greek Reading Tasks

The scoring for reading fluency is a composite score (errors, time and words non-read) and is divided by 10 in this figure, while word and non-word reading is in percentage of errors. The higher the scores the lower the performance.

As far as the difference in the performance of the bilingual adults in Greek and Italian tasks is concerned, they both had better performance in Greek than in Italian in decoding tasks (word 
reading: $1,6 \%$ and $0,6 \%$ vs. $19,6 \%$ and $3,6 \%$ for bi-DD and bi-TD respectively; non-word reading: $7,3 \%$ and $2,1 \%$ vs. $15,9 \%$ and $5,7 \%$ for bi-DD and bi-TD respectively). The opposite was found for non-word repetition, where they both had better performance in Italian than Greek ( $75 \%$ and $58 \%$ vs. $69 \%$ and $14 \%$ for bi-DD and bi-TD respectively). In Figure 2 the performance in all tasks in both languages are illustrated.

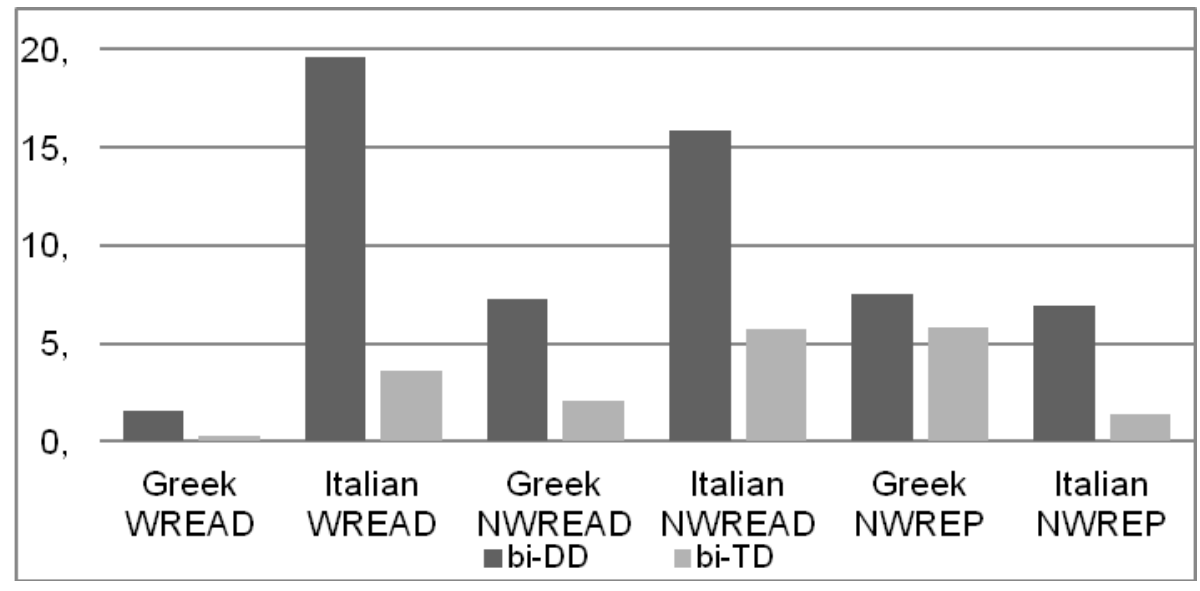

Figure 2. Performance of the Bilingual Participants (bi-DD and bi-TD) on the Greek and Italian Tasks

Percentages of errors in decoding and non-word repetition in Greek and Italian. Non-word repetition scores (in Greek and in Italian) are divided by 10 in this figure. The higher the scores the lower the performance. Bi-DD: bilingual dyslexic, bi-TD: bilingual typically developing, WREAD: word reading, NWREAD: non-word reading, NWREP: non-word repetition.

\section{Discussion}

In the present study, we examined bilingual dyslexia in two transparent orthographies (Italian and Greek). The aim of the study was to explore whether there are cross-linguistic differences in the performance of bilingual individuals with and without dyslexia in word and non-word reading and phonological STM (non-word repetition) skills. We also explored whether the amount of exposure in both languages or the dominance of one of the two languages affect the manifestation of reading and phonological STM deficits and how. Moreover, it aimed to examine whether there is a (positive or negative) effect of bilingualism in the manifestation of the deficits in dyslexia. For this reason, we assessed two dyslexic adults, one bilingual and one monolingual and two TD adults, one bilingual and one monolingual.

The results showed that the performance of the bilingual adult with dyslexia was significantly poorer than that of the TD bilingual adult on all tasks in both languages, suggesting that dyslexia affects similarly decoding and phonological STM across languages. Moreover, the 
bilingual dyslexic adult performed better than the monolingual dyslexic adult in all tasks, while for TD adults the pattern was different. Bilingual TD adult performed better than monolingual TD only in non-word repetition, whereas monolingual TD adult performed better than the bilingual one in all reading tasks (reading fluency, word and non-word reading). These results suggest that bilingualism was beneficial for dyslexics for reading and non-word repetition but for TD adults it was only beneficial for non-word repetition. The fact that bilingual dyslexic outperformed monolingual dyslexic adult is in line with studies in word reading (Abu-Rabia \& Siegel, 2002) and non-word reading (Abu-Rabia \& Siegel, 2002; Lallier et al., 2018). However, it does not corroborate studies in which better performance of monolingual dyslexics as compared to bilingual dyslexics is found in word reading (Zanzurino et al., 2012) and non-word repetition (Vender et al., 2016; 2019). The better performance of the bilingual TD adult as compared to bilingual dyslexic adult in reading and non-word repetition was expected and corroborated the results found in the literature (Swanson et al., 2006; Oren \& Breznitz, 2005; but see Hedman, 2012 for similar performance between bilingual dyslexics and bilingual TD adolescences).

However, our results found for TD adults are somehow contradictory: bilingualism was beneficial only for non-word repetition, in which bilingual TD adult had better performance than monolingual TD adult, in accordance to the findings by Tamburelli et al. (2005). In contrast, in word and non-word reading and reading fluency the monolingual TD adult outperformed bilingual TD adult. This finding, also found in other studies (e.g. Bonifacci et al., 2017), might imply that bilingualism moderates reading deficits in dyslexics, but it does not help typical readers. In contrast, the bilingual advantage in phonological STM skills was evident for both dyslexic and TD adults, who outperformed their monolingual counterparts. This finding, however, does not annul the fact that a phonological STM deficit was present for both dyslexic adults. It only means that this deficit was modulated in the bilingual dyslexic.

As regards the cross-linguistic differences in reading and phonological STM skills between L1 and L2, both bilingual adults had better word and non-word reading skills in Greek, which was their dominant language, than in Italian. According to the literature, bilingual individuals perform better in their dominant language (Bonfieni et al., 2019; Dickinson \& Porsche, 2011; Monaghan et al., 2017; Nota, 2018; Papastefanou et al., 2019; Thordardottir, 2011). However, in non-word repetition they performed better in Italian than in Greek. This could be explained by the peculiarities of the Greek orthography -which compared to Italian has a variety of inconsistencies- and by its more complex phonotactic structure (for review see Protopapas, 2017). Consequently, despite the fact that both Greek and Italian are languages with a transparent orthography, the performance in reading and non-word repetition was not the same across the two languages for the two bilingual adults. It seems that although the language dominance affects performance in reading, it does not affect performance in phonological STM, which depends more on phonological skills and is affected by phonotactic complexity.

In sum, we suggest that the language dominance and the orthographic transparency must be considered when assessing reading and STM skills in bilingual individuals with and without dyslexia, but phonotactic complexity of L1 (or L2) may influence their performance. However, 
limitations of this study, such as the small number of subjects, should be taken into account to avoid over-generalization of the results.

\section{Conclusion}

The present study addressed three questions. The first question was whether there are differences in the performance of bilingual individuals with and without dyslexia in word and non-word reading and phonological STM skills between two transparent languages, Greek and Italian. The second question was whether the dominance of one of the two languages affect the manifestation of reading and phonological STM deficits in dyslexia and how and the third was whether there is an effect of bilingualism in the performance. On reading, inverse patterns of performance were found for dyslexics and TD, since bilingual dyslexic outperformed monolingual dyslexic and monolingual TD outperformed bilingual TD adult. In contrast, on phonological STM, both bilinguals outperformed monolinguals. A positive effect of bilingualism was found for reading skills only for dyslexics, while for phonological STM skills it was found for both dyslexics and TD. Finally, for both bilinguals the dominance of L1 affected the manifestation of the performance in reading but not in phonological STM.

These results have clear implications for future studies in this area. They accentuate the fact that in bilingualism phonological skills depend on factors other than the language dominance and the orthographic transparency and they highlight the key role of the phonotactic complexity of a language. Future research in bilingual dyslexia need to take this parameter into consideration. Our results have also clinical implications. These include intervention programs that train phonological reading-related skills, such as phonological STM, along with reading skills of individuals with dyslexia.

\section{Acknowledgements}

The authors would like to thank Prof. Stavroula Stavrakaki for the supervision of the present study and useful comments on the manuscript.

\section{References}

Abu-Rabia, S., \& Siegel, L. S. (2002). Reading, syntactic, orthographic, and working memory skills of bilingual Arabic-English speaking Canadian children. Journal of Psycholinguistic Research, 31(6), 661-678. https://doi.org/10.1023/A:1021221206119

Abu-Rabia, S., \& Siegel, L. S. (2003). Reading skills in three orthographies: The case of trilingual Arabic-Hebrew-English-speaking Arab children. Reading and Writing, 16(7), 611-634. https://doi.org/10.1023/A:1025838029204

Anastasiou, D., \& Protopapas, A. (2015). Difficulties in lexical stress versus difficulties in segmental phonology among adolescents with dyslexia. Scientific Studies of Reading, 
19(1), 31-50. https://doi.org/10.1080/10888438.2014.934452

Barca, L., Burani, C., Di Filippo, G., \& Zoccolotti, P. (2006). Italian developmental dyslexic and proficient readers: where are the differences? Brain and Language, 98, 347-351. https://doi.org/10.1016/j.bandl.2006.05.001

Bellocchi, S., Tobia, V., \& Bonifacci, P. (2017). Predictors of reading and comprehension abilities in bilingual and monolingual children: a longitudinal study on a transparent language. Reading and Writing, 30(6), 1311-1334. https://doi.org/10.1007/s11145-017-9725-5

Beneventi, H., Tønnessen, F. E., Ersland, L., \& Hugdahl, K. (2010). Executive working memory processes in dyslexia: Behavioral and fMRI evidence. Scandinavian Journal of Psychology, 51, 192-202. https://doi.org/10.1111/j.1467-9450.2010.00808.x

Bertelli, B., \& Bilancia, G. (2006). VAUMeLF. Batterie per la valutazione dell'attenzione uditiva e della memoria di lavoro fonologica nell'eta 'evolutiva. Firenze: Giunti-O.S.

Bialystok, E., \& Luk, G. (2012). Receptive vocabulary differences in monolingual and bilingual adults. Bilingualism: Language and Cognition, 15(2), 397-401. https://doi.org/10.1017/S136672891100040X

Bialystok, E., Luk, G., Peets, K. F., \& Yang, S. (2010). Receptive vocabulary differences in monolingual and bilingual children. Bilingualism: Language and Cognition, 13(4), 525-531. https://doi.org/10.1017/S1366728909990423

Bialystok, E., McBride-Chang, C., \& Luk, G. (2005). Bilingualism, language proficiency, and learning to read in two writing systems. Journal of Educational Psychology, 97(4), 580590. https://doi.org/10.1037/0022-0663.97.4.580

Bonfieni, M., Branigan, H. P., Pickering, M. J., \& Sorace, A. (2019). Language experience modulates bilingual language control: The effect of proficiency, age of acquisition, and exposure on language switching. Acta Psychologica, 193, 160-170. https://doi.org/10.1016/j.actpsy.2018.11.004

Bonifacci, P., Canducci, E., Gravagna, G., \& Palladino, P. (2017). English as a foreign language in bilingual language-minority children, children with dyslexia and monolingual typical readers. Dyslexia, 23(2), 181-206. https://doi.org/10.1002/dys.1553

Brizzolara, D., Casalini, C., Gasperini, F., Roncoli, S., Mazzotti, S., Cipriani, P., \& Chilosi, A. M. (2006). A follow-up study of reading and writing in Italian children with specific language impairment. In D. Riva, I. Rapin \& G. Zardini (Eds.), Language: Normal and Pathological Development (pp. 239-252). Montrouge: John Libbey Eurotext.

Bruck, M. (1992). Persistence of dyslexics' phonological awareness deficits. Developmental Psychology, 28, 874-886. https://doi.org/10.1037/0012-1649.28.5.874

Brunswick, N. (2010). Unimpaired reading development and dyslexia across different languages. In N. Brunswick, S. McDougall, P. de Mornay Davies (Eds.), Reading and 
dyslexia in different orthographies (pp. 149-172). London: Psychology Press.

Burani, C., Marcolini, S., \& Stella, G. (2002). How early does morpholexical reading develop in readers of a shallow orthography? Brain and Language, 81(1-3), 568-586. https://doi.org/10.1006/brln.2001.2548

Carroll, J. M., \& Snowling, M. J. (2004). Language and phonological skills in children at high risk of reading difficulties. Journal of Child Psychology and Psychiatry, 45, 631-640. https://doi.org/10.1111/j.1469-7610.2004.00252.x

Chilosi, A. M., Brizzolara, D., Lami, L., Pizzoli, C., Gasperini, F., Pecini, C., ... \& Zoccolotti, P. (2009). Reading and spelling disabilities in children with and without a history of early language delay: a neuropsychological and linguistic study. Child Neuropsychology, 15(6), 582-604. https://doi.org/10.1080/09297040902927614

Chilosi, A. M., Lami, L., Pizzoli, C., Pignatti, B., D'Alessandro, D., Gruppioni, B., ... \& Brizzolara, D. (2003). Profili neuropsicologici nella dislessia evolutiva. Psicologia Clinica dello Sviluppo, 7(2), 269-286. https://doi.org/10.1449/9691

Chung, K. K. H., \& Ho, C. S. (2010). Second Language Learning Difficulties in Chinese Children With Dyslexia: What Are the Reading-Related Cognitive Skills That Contribute to English and Chinese Word Reading? Journal of Learning Disabilities, 43(3), 195-211. https://doi.org/10.1177/0022219409345018

Cline, T. (2000). Multilingualism and dyslexia: Challenges for research and practice. Dyslexia, $6(1)$, $3-12$. https://doi.org/10.1002/(SICI)1099-0909(200001/03)6:1<3::AID-DYS156>3.0.CO;2-E

Coltheart, M. (1978). Lexical access in simple reading task. In G. Underwood (Ed.), Strategies of information processing (pp. 151-216). London: Academic Press.

Coltheart, M., Rastle, K., Perry, C., Langdon, R., \& Ziegler, J. (2001). DRC: a dual route cascaded model of visual word recognition and reading aloud. Psychological review, 108(1), 204-256. https://doi.org/10.1037/0033-295X.108.1.204

Constantinidou, F., \& Evripidou, C. (2012). Stimulus modality and working memory performance in Greek children with reading disabilities: Additional evidence for the pictorial superiority hypothesis. Child Neuropsychology, 18(3), 256-280. https://doi.org/10.1080/09297049.2011.602013

Constantinidou, M., \& Stainthorp, R. (2009). Phonological awareness and reading speed deficits in reading disabled Greek-speaking children. Educational Psychology, 29(2), 171-186. https://doi.org/10.1080/01443410802613483

Da Fontoura, H. A., \& Siegel, L. S. (1995). Reading, syntactic, and working memory skills of bilingual Portuguese-English Canadian children. Reading and Writing, 7(1), 139-153. https://doi.org/10.1007/BF01026951

De Luca, M., Barca, L., Burani, C., \& Zoccolotti, P. (2008). The effect of word length and 
other sublexical, lexical, and semantic variables on developmental reading deficits. Cognitive and Behavioral Neurology, 21(4), 227-235. https://doi.org/10.1097/WNN.0b013e318190d162

Diamanti, V., Goulandris, N., Stuart, M., Campbell, R., \& Protopapas, A. (2018). Tracking the effects of dyslexia in reading and spelling development: A longitudinal study of Greek readers. Dyslexia, 24(2), 170-189. https://doi.org/10.1002/dys.1578

Dickinson, D. K., \& Porche, M. V. (2011). Relation between language experiences in preschool classrooms and children's kindergarten and fourth-grade language and reading $\begin{array}{llll}\text { abilities. Child } & \text { Development, } & \text { 82(3), }\end{array}$ https://doi.org/10.1111/j.1467-8624.2011.01576.x

Dulude, L. (2012). Writing systems, phonemic awareness, and bilingualism: cross-linguistic issues in dyslexia. Indiana University Undergraduate Journal of Cognitive Science, 7, 22-30.

Facoetti, A., Zorzi, M., Cestnick, L., Lorusso, M. L., Molteni, M., Paganoni, P., ... \& Mascetti, G. G. (2006). The relationship between visuo-spatial attention and nonword reading in developmental dyslexia. Cognitive Neuropsychology, 23(6), 841-855. https://doi.org/10.1080/02643290500483090

Gangl, M., Moll, K., Jones, M. W., Banfi, C., Schulte-Körne, G., \& Landerl, K. (2018). Lexical reading in dysfluent readers of German. Scientific Studies of Reading, 22(1), 24-40. https://doi.org/10.1080/10888438.2017.1339709

Georgas, D. D., Paraskevopoulos, I. N., Bezevegis, I. G., \& Giannitsas, N. D. (1997). Greek WISC-III: Wechsler intelligence scales for children. Athens: Ellinika Grammata.

Geva, E., \& Siegel, L. S. (2000). Orthographic and cognitive factors in the concurrent development of basic reading skills in two languages. Reading and Writing, 12(1-2), 1-30. https://doi.org/10.1023/A:1008017710115.

Hedman, C. (2012). Profiling dyslexia in bilingual adolescents. International Journal of $\begin{array}{lll}\text { Speech-Language Pathology, } & \text { 14(6), }\end{array}$ https://doi.org/10.3109/17549507.2012.693201

Helmuth, L. (2001). Dyslexia: Same Brains, Different Languages. Science, 291(5511), 2064-2065. https://doi.org/10.1126/science.291.5511.2064

Jalali-Moghadam, N., \& Kormi-Nouri, R. (2017). Bilingualism and reading difficulties: an exploration in episodic and semantic memory. Journal of Cognitive Psychology, 29(5), 570-582. https://doi.org/10.1080/20445911.2017.1293673

Jiménez González, J. E., \& Hernández Valle, I. (2000). Word identification and reading disorders in the Spanish language. Journal of Learning disabilities, 33(1), 44-60. https://doi.org/10.1177/002221940003300108

Johansson, B. B. (2006). Cultural and linguistic influence on brain organization for language 
and possible consequences for dyslexia: A review. Annals of Dyslexia, 56(1), 13-50. https://doi.org/10.1007/s11881-006-0002-6

Kormi-Nouri, R., Moradi, A. R., Moradi, S., Akbari-Zardkhaneh, S., \& Zahedian, H. (2012). The effect of bilingualism on letter and category fluency tasks in primary school children: Advantage or disadvantage?. Bilingualism: Language and Cognition, 15(2), 351-364. https://doi.org/10.1017/S1366728910000192

Kovelman, I., Baker, S. A., \& Petitto, L. A. (2008). Age of first bilingual language exposure as a new window into bilingual reading development. Bilingualism: Language and Cognition, 11(2), 203-223. https://doi.org/10.1017/S1366728908003386

Lallier, M., \& Carreiras, M. (2018). Cross-linguistic transfer in bilinguals reading in two alphabetic orthographies: The grain size accommodation hypothesis. Psychonomic Bulletin \& Review, 25(1), 386-401. https://doi.org/10.3758/s13423-017-1273-0

Lallier, M., Thierry, G., Barr, P., Carreiras, M., \& Tainturier, M. J. (2018). Learning to read bilingually modulates the manifestations of dyslexia in adults. Scientific Studies of Reading, 22(4), 335-349. https://doi.org/10.1080/10888438.2018.1447942

Landerl, K., Wimmer, H., \& Frith, U. (1997). The impact of orthographic consistency on dyslexia: A German-English comparison. Cognition, 63, 315-334. https://doi.org/10.1016/S0010-0277(97)00005-X

Landerl, K., Ramus, F., Moll, K., Lyytinen, H., Leppänen, P. H., Lohvansuu, K., ... \& Kunze, S. (2013). Predictors of developmental dyslexia in European orthographies with varying complexity. Journal of Child Psychology and Psychiatry, 54(6), 686-694. https://doi.org/10.1111/jcpp.12029

Lefavrais, P. (1967/2005). Test de l'Alouette [The Alouette Test]. Paris: Les Editions du Centre de Psychologie Appliquée.

Lesaux, N. K., \& Siegel, L. S. (2003). The development of reading in children who speak English as a second language. Developmental psychology, 39(6), 1005. https://doi.org/10.1037/0012-1649.39.6.1005

Lyon, G. R., Shaywitz, S. E., \& Shaywitz, B. A. (2003). A definition of dyslexia. Annals of dyslexia, 53(1), 1-14. https://doi.org/10.1007/s11881-003-0001-9

Martelli, M., De Luca, M., Lami, L., Pizzoli, C., Pontillo, M., Spinelli, D., \& Zoccolotti, P. (2014). Bridging the gap between different measures of the reading speed deficit in developmental dyslexia. Experimental Brain Research, 232(1), 237-252. https://doi.org/10.1007/s00221-013-3735-6

Martin, J., Colé, P., Leuwers, C., Casalis, S., Zorman, M., \& Sprenger-Charolles, L. (2010). Reading in French-speaking adults with dyslexia. Annals of Dyslexia, 60(2), 238-264. https://doi.org/10.1007/s11881-010-0043-8

Melby-Lervåg, M., \& Lervåg, A. (2011). Cross-linguistic transfer of oral language, decoding, 
phonological awareness and reading comprehension: A meta-analysis of the correlational evidence. Journal of Research in Reading, 34(1), 114-135. https://doi.org/10.1111/j.1467-9817.2010.01477.x

Mengisidou, M., \& Marshall, C. R. (2019). Deficient explicit access to phonological representations explains phonological fluency difficulties in Greek children with dyslexia and/or developmental language disorder. Frontiers in Psychology, 10, 638. https://doi.org/10.3389/fpsyg.2019.00638

Monaghan, P., Chang, Y. N., Welbourne, S., \& Brysbaert, M. (2017). Exploring the relations between word frequency, language exposure, and bilingualism in a computational model of reading. Journal of Memory and Language, 93, 1-21. https://doi.org/10.1016/j.jml.2016.08.003

Nikolopoulos, D., Goulandris, N., Hulme, C., \& Snowling, M. J. (2006). The cognitive bases of learning to read and spell in Greek: Evidence from a longitudinal study. Journal of Experimental Child Psychology, 94, 1-17. https://doi.org/10.1016/j.jecp.2005.11.006

Nota, N. (2018). The Effect of Bilingualism on Frisian-Dutch Children's Reading: An Eye-Tracking Study. Master Thesis, Leiden University, Netherlands.

Oren, R., \& Breznitz, Z. (2005). Reading processes in L1 and L2 among dyslexic as compared to regular bilingual readers: Behavioral and electrophysiological evidence. $\begin{array}{lll}\text { Journal of } & \text { Neurolinguistics, } & 18(2),\end{array}$ https://doi.org/10.1016/j.jneuroling.2004.11.003

Orsolini, M., Fanari, R., Cerracchio, S., \& Famiglietti, L. (2009). Phonological and lexical reading in Italian children with dyslexia. Reading and Writing, 22(8), 933. https://doi.org/10.1007/s11145-008-9134-x

Pagliuca, G., Arduino, L. S., Barca, L., \& Burani, C. (2008). Fully transparent orthography, yet lexical reading aloud: The lexicality effect in Italian. Language and Cognitive processes, 23(3), 422-433. https://doi.org/10.1080/01690960701626036

Paizi, D., De Luca, M., Zoccolotti, P., \& Burani, C. (2013). A comprehensive evaluation of lexical reading in Italian developmental dyslexics. Journal of Research in Reading, 36(3), 303-329. https://doi.org/10.1111/j.1467-9817.2011.01504.x

Paizi, D., Zoccolotti, P., \& Burani, C. (2011). Lexical stress assignment in Italian developmental dyslexia. Reading and Writing, 24(4), 443-461. https://doi.org/10.1007/s11145-010-9236-0

Papastefanou, T., Powell, D., \& Marinis, T. (2019). Language and decoding skills in Greek-English primary school bilingual children: effects of language dominance, contextual factors and cross-language relationships between the heritage and the majority language. Frontiers in Communication, 4, 65. https://doi.org/10.3389/fcomm.2019.00065

Paraskevaidis, N. (2010). Norms for the tasks of assessment of verbal working memory with the task of words and nonwords recall. Master thesis, Department of Psychology, Aristotle 
University of Thessaloniki.

Paulesu, E., Demonet, J., Fazio, F., McCrory, E., Chanoine, V., \& Brunswick, N., et al. (2001). Dyslexia: cultural diversity and biological unity. Science, 291, 2165-2167. https://doi.org/10.1126/science.1057179

Pennington, B. F., \& Lefly, D. L. (2001). Early reading development in children at family risk for dyslexia. Child Development, 72, 816-833. https://doi.org/10.1111/1467-8624.00317

Pickering, S., \& Gathercole, S. E. (2001). Working memory test battery for children $(W M T B-C)$. Psychological Corporation.

Porpodas, C. D. (1999). Patterns of phonological and memory processing in beginning readers and spellers of Greek. Journal of Learning Disabilities, 32, 406-416. https://doi.org/10.1177/002221949903200506

Protopapas, A. (2017). Learning to read Greek. In L. T. W. Verhoeven \& C. A. Perfetti (Eds.), Learning to read across languages and writing systems (pp. 155-180). Cambridge University Press.

Protopapas, A., \& Skaloumbakas, C. (2007). Traditional and computer-based screening and diagnosis of reading disabilities in Greek. Journal of Learning Disabilities, 40(1), 15-36. https://doi.org/10.1177/00222194070400010201

Protopapas, A., \& Skaloumbakas, C. (2008). Assessment of reading fluency for the identification of reading difficulties. Psychologia, 15(3), 267-289.

Rack, J. P. (2017). Dyslexia: The phonological deficit hypothesis. In A. Fawcett \& R. Nicolson (Eds.), Dyslexia in children: Multidisciplinary perspectives (pp. 5-37). London: Routledge.

Rack, J. P., Snowling, M. J., \& Olson, R. K. (1992). The nonword reading deficit in developmental dyslexia: A review. Reading Research Quarterly, 27, 29-53. https://doi.org/10.2307/747832

Ramus, F., \& Szenkovits, G. (2008). What phonological deficit?. The Quarterly Journal of Experimental Psychology, 61(1), 129-141. https://doi.org/10.1080/17470210701508822

Ramus, F., Rosen, S., Dakin, S. C., Day, B. L., Castellote, J. M., White, S., \& Frith, U. (2003). Theories of developmental dyslexia: insights from a multiple case study of dyslexic adults. Brain, 126, 841-865. https://doi.org/10.1093/brain/awg076

Roodenrys, S., \& Stokes, J. (2001). Serial recall and nonword repetition in reading disabled children. Reading and Writing: An Interdisciplinary Journal, 14, 379-394. https://doi.org/10.1023/A:1011123406884

Sartori, G., Job, R., \& Tressoldi, P. E. (2007). DDE - 2. Batteria per la valutazione della Dislessia e Disortografia Evolutiva -2. Firenze: Giunti O.S. 
Seymour, P. H., Aro, M., Erskine, J. M., \& Collaboration with COST Action A8 Network. (2003). Foundation literacy acquisition in European orthographies. British Journal of psychology, 94(2), 143-174. https://doi.org/10.1348/000712603321661859

Siegel, L. (2016). Bilingualism and Dyslexia: The case of children learning English as an additional language. In L. Peer \& G. Reid (Eds.) Multilingualism, Literacy and Dyslexia (pp. 137-147). Routledge.

Snowling, M. (1998). Dyslexia as a phonological deficit: Evidence and implications. Child Psychology and Psychiatry Review, 3(1), 4-11. https://doi.org/10.1017/S1360641797001366

Snowling, M., Nation, K., Moxham, P., Gallagher, A., \& Frith, U. (1997). Phonological processing skills of dyslexic students in higher education: A preliminary report. Journal of Research in Reading, 20(1), 31-41. https://doi.org/10.1111/1467-9817.00018

Spanoudis, G. C., Papadopoulos, T. C., \& Spyrou, S. (2019). Specific language impairment and reading disability: Categorical distinction or continuum? Journal of learning disabilities, 52(1), 3-14. https://doi.org/10.1177/0022219418775111

Sparks, R. L., Patton, J., Ganschow, L., Humbach, N., \& Javorsky, J. (2006). Native language predictors of foreign language proficiency and foreign language aptitude. Annals of Dyslexia, 56(1), 129-160. https://doi.org/10.1007/s11881-006-0006-2

Spinelli, D., De Luca, M., Di Filippo, G., Mancini, M., Martelli, M., \& Zoccolotti, P. (2005). Length effect in word naming latencies: Role of reading experience and reading deficit. Developmental Neuropsychology, 217-235. https://doi.org/10.1207/s15326942dn2702_2

Sprenger-Charolles, L. (2019). Developmental Dyslexia in French. In L. Verhoeven, C. Perfetti \& K. Pugh (Eds.), Developmental Dyslexia across Languages and Writing Systems, (pp. 50-72). Cambridge University Press. https://doi.org/10.1017/9781108553377.003

Sprenger-Charolles, L., Colé, P., Kipffer-Piquard, A., Pinton, F., \& Billard, C. (2009). Reliability and prevalence of an atypical development of phonological skills in French-speaking dyslexics. Reading and Writing, 22(7), 811-842. https://doi.org/10.1007/s11145-008-9117-y

Sprenger-Charolles, L., Siegel, L. S., Jimenez, J. E., \& Ziegler, J. C. (2011). Prevalence and reliability of phonological, surface, and mixed profiles in dyslexia: A review of studies conducted in languages varying in orthographic depth. Scientific Studies of Reading, 15(6), 498-521. https://doi.org/10.1080/10888438.2010.524463

Sprenger-Charolles, L., Colé, P., \& Serniclaes, W. (2013). Reading acquisition and developmental dyslexia. Psychology Press.

Sullivan, M. D., Poarch, G. J., \& Bialystok, E. (2018). Why is lexical retrieval slower for bilinguals? Evidence from picture naming. Bilingualism: Language and Cognition, 
21(3), 479-488. https://doi.org/10.1017/S1366728917000694

Swanson, H. L., Sáez, L., Gerber, M., \& Leafstedt, J. (2004). Literacy and Cognitive Functioning in Bilingual and Nonbilingual Children at or Not at Risk for Reading Disabilities. Journal of Educational Psychology, 96(1), 3-18.

Swanson, H. L., Sáez, L., \& Gerber, M. (2006). Growth in literacy and cognition in bilingual children at risk or not at risk for reading disabilities. Journal of Educational Psychology, 98(2), 247-264. https://doi.org/10.1037/0022-0663.96.1.3

Talli, I. (2010). Linguistic abilities in developmental dyslexia and specific language impairment (SLI): A comparative and cross-linguistic approach. Doctoral dissertation, Université Paris Descartes \& Aristotle University of Thessaloniki.

Talli, I., Sprenger-Charolles, L., \& Stavrakaki, S. (2016). Specific language impairment and developmental dyslexia: What are the boundaries? Data from Greek children. Research in Developmental Disabilities, 49, 339-353. https://doi.org/10.1016/j.ridd.2015.12.014

Tamburelli, M., Sanoudaki, E., Jones, G., \& Sowinska, M. (2015). Acceleration in the bilingual acquisition of phonological structure: Evidence from Polish-English bilingual children. Bilingualism: Language and Cognition, 18(4), 713-725. https://doi.org/10.1017/S1366728914000716

Thordardottir, E. (2011). The relationship between bilingual exposure and vocabulary development. International Journal of Bilingualism, 15(4), 426-445. https://doi.org/10.1177/1367006911403202

Tressoldi, P. E., Stella, G., \& Faggella, M. (2001). The development of reading speed in Italians with dyslexia: A longitudinal study. Journal of Learning Disabilities, 34, 414-417. https://doi.org/10.1177/002221940103400503

Vellutino, F. R., Fletcher, J. M., Snowling, M. J., \& Scanlon, D. M. (2004). Specific reading disability (dyslexia): What have we learned in the past four decades?. Journal of child $\begin{array}{llll}\text { psychology and } \quad \text { asychiatry, } & \text { 45(1), }\end{array}$ https://doi.org/10.1046/j.0021-9630.2003.00305.x

Vender, M., Delfitto, D., \& Melloni, C. (2019). How do bilingual dyslexic and typically developing children perform in nonword repetition? Evidence from a study on Italian L2 children. Bilingualism: Language and Cognition, 1-13. https://doi.org/10.1017/S1366728919000828

Vender, M., Mantione, F., Savazzi, S., Delfitto, D., \& Melloni, C. (2017). Inflectional morphology and dyslexia: Italian children's performance in a nonword pluralization task. Annals of dyslexia, 67(3), 401-426. https://doi.org/10.1007/s11881-017-0152-8

Vender, M., Garraffa, M., Sorace, A., \& Guasti, M. T. (2016). How early L2 children perform on Italian clinical markers of SLI: A study of clitic production and nonword repetition. $\begin{array}{llll}\text { Clinical Linguistics } \& \text { Phonetics, } & \text { 30(2), } & \text { 150-169. }\end{array}$ https://doi.org/10.3109/02699206.2015.1120346 
Wimmer, H. (1993). Characteristics of developmental dyslexia in a regular writing system. Applied psycholinguistics, 14(1), 1-33. https://doi.org/10.1017/S0142716400010122

Wimmer, H. (2006). Don't neglect reading fluency! Developmental Science, 9(5), 447-448. https://doi.org/10.1111/j.1467-7687.2006.00527.x

Wimmer, H., Mayringer, H., \& Landerl, K. (1998). Poor reading: A deficit in skill-automatization or a phonological deficit? Scientific Studies of Reading, 2(4), 321-340. https://doi.org/10.1207/s1532799xssr0204_2

Zanzurino, F. G., Scortichini, F., Giacomo, S., Morlini, I., \& Scorza, M. (2012). La diagnosi di dislessia e disortografia evolutiva nei bambini bilingui (L2). Evidenze sul ruolo del lessico. Dislessia, 9(3), 319-339.

Zhang, D., Chin, C. F., \& Li, L. (2017). Metalinguistic awareness in bilingual children's word reading: A cross-lagged panel study on cross-linguistic transfer facilitation. Applied Psycholinguistics, 38(2), 395-426. https://doi.org/10.1017/S0142716416000278

Ziegler, J. C., \& Goswami, U. (2005). Reading acquisition, developmental dyslexia, and skilled reading across languages: a psycholinguistic grain size theory. Psychological bulletin, 131(1), 3-29. https://doi.org/10.1037/0033-2909.131.1.3

Ziegler, J. C., Perry, C., Ma-Wyatt, A., Ladner, D., \& Schulte-Körne, G. (2003). Developmental dyslexia in different languages: Language-specific or universal?. Journal of Experimental Child Psychology, 86(3), 169-193. https://doi.org/10.1016/S0022-0965(03)00139-5

Zoccolotti, P., De Luca, M., \& Spinelli, D. (2015). Discrete versus multiple word displays: A re-analysis of studies comparing dyslexic and typically developing children. Frontiers in Psychology, 6, 1530. https://doi.org/10.3389/fpsyg.2015.01530

Zoccolotti, P., De Luca, M., Di Pace, E., Gasperini, F., Judica, A., \& Spinelli, D. (2005). Word length effect in early reading and in developmental dyslexia. Brain and Language, 93, 369-373. https://doi.org/10.1016/j.band1.2004.10.010

Zoccolotti, P., De Luca, M., Di Pace, E., Judica, A., Orlandi, M., \& Spinelli, D. (1999). Markers of developmental surface dyslexia in a language (Italian) with high grapheme-phoneme correspondence. Applied Psycholinguistics, 20(2), 191-216. https://doi.org/10.1017/S0142716499002027

Zoccolotti, P., De Luca, M., Judica, A., \& Burani, C. (2006). Delayed naming cancels the word length effect in developmental dyslexia. Brain and Language, 99(1-2), 36-37. https://doi.org/10.1016/j.bandl.2006.06.028

Zoccolotti, P., De Luca, M., Judica, A., \& Spinelli, D. (2008). Isolating global and specific factors in developmental dyslexia: a study based on the rate and amount model (RAM). Experimental Brain Research, 186(4), 551-560. https://doi.org/10.1007/s00221-007-1257-9 


\section{Copyright Disclaimer}

Copyright for this article is retained by the author(s), with first publication rights granted to the journal.

This is an open-access article distributed under the terms and conditions of the Creative Commons Attribution license (http://creativecommons.org/licenses/by/3.0/). 